\title{
Integrating Case Studies in an Online Asynchronous Learning Environment: An Empirical Study to Evaluate the Effect on Community College Student Learning Outcomes and Engagement when Case Studies are Presented Using Virtual Reality
}

\author{
Dr. Kapil Chalil Chalil Madathil, Clemson University
}

Dr. Kapil Chalil Madathil's area of expertise is in applying the knowledge base of human factors engineering to the design and operation of human-computer systems that involve rich interactions among people and technology. His research covers the entire spectrum of system design: from identifying the user needs to designing and developing systems that inform and motivate user behavior and empirically evaluating the efficacy of these interventions. He draws on qualitative and quantitative methodologies including ethnography, contextual inquiry, surveys and controlled behavioral experiments to understand how humans perceive, make sense of, and interact with complex human-machine systems.

\section{Dr. Kristin Kelly Frady, Clemson University}

Dr. Kris Frady is the Director of Operations for the Clemson University Center for Workforce Development. Additionally, she has earned experience in the corporate sector working with Blackbaud Inc., designing and delivering professional training seminars in online, blended, and live environments. She also has experience in the educational sector in both live and online environments as an adjunct instructor in computer technology for Greenville Technical College and as a Career and Technology Education teacher.

Kris earned a B.S. in Management from Clemson University, a Masters of Arts in Teaching in Business Education from the University of South Carolina, and an Ed.D. in Curriculum and Instruction with an emphasis in Educational Technology and online learning from the University of Florida.

Her research interests include implementation of digital learning solutions in technical and vocational education, development of career pathways utilizing stackable certificates, educator professional development in communities of practice, and analysis of economic development and industry factors impacting education and workforce development.

She is a licensed South Carolina Educator and serves on various boards to assist with implementation of workforce development is a statewide model including: the Anderson, Oconee, Pickens Showcase board, the technical college led Partnership for Academic and Career Education, Oconee County Work Ready Community Board of Advisors, and Pickens Career and Technology Center Advisory Board.

In over 10 years in development of educational and training materials Kris has designed and delivered professional development and training courses and seminars for 501-c3 organizations across the United States. Her experience as a professional educator has supported her development of educational resources, knowledge of P-12 and technical college systems and needs, and passion for educating youth. In her role as Director of Operations for the Center for Workforce Development she has guided development and assessment of innovative online educational material and the integration of digital learning and visualization tools. She has been part of a team involved in disseminating those results and models throughout numerous national conferences and peer reviewed conference papers. Finally, as part of an overall team she has worked to develop a system wide support network consisting of all 16 South Carolina technical colleges, state funded organizations, National Science Foundation Advanced Technological Education Centers across the United States, P-12 schools and districts across South Carolina, and many manufacturing industry partners to create pathways and resources for supporting advanced manufacturing advocacy and opportunities impacting employability and economic development across the Southeast.

\section{Dr. Anand K. Gramopadhye, Clemson University}

Dr. Anand K. Gramopadhye's research focuses on solving human-machine systems design problems and modeling human performance in technologically complex systems such as health care, aviation and manufacturing. He has more than 200 publications in these areas, and his research has been funded by NIH, 
NASA, NSF, FAA, DOE, and private companies. Currently, he and his students at the Advanced Technology Systems Laboratory are pursuing cutting-edge research on the role of visualization and virtual reality in aviation maintenance, hybrid inspection and job-aiding, technology to support STEM education and, more practically, to address information technology and process design issues related to delivering quality health care. As the Department Chair, he has been involved in the initiation of programmatic initiatives that have resulted in significant growth in the Industrial Engineering Program, situating it in the forefront both nationally and internationally. These include the Online Master of Engineering in Industrial Engineering Program, the Endowed Chairs Program in Industrial Engineering, Human Factors and Ergonomics Institute and the Clemson Institute for Supply Chain and Optimization and the Center for Excellence in Quality. For his success, he has been recognized by the NAE through the Frontiers in Engineering Program, and he has received the College's Collaboration Award and the McQueen Quattlebaum Award, which recognizes faculty for their outstanding research. In addition, Dr. Gramopadhye serves as Editor-in-Chief of the International Journal of Industrial Ergonomics and on the editorial board for several other journals.

\section{Mr. Jeff Bertrand}

\section{Dr. Rebecca S Hartley, Clemson University Center for Workforce Development}

Rebecca Hartley has spent the past seventeen years working in higher education administration in the areas of undergraduate admissions, graduate admissions, academic records, and student affairs. She holds a Ph.D. in Public Administration and Public Policy from Auburn University. Prior to joining the Clemson University Center for Workforce Development as the Director of Pathways, she served as Director of Graduate Admissions \& Records at the University of Montevallo in Alabama. Her research interest and expertise focuses on citizen public opinion as it relates to federal and state public policy. Additionally, her research focus includes how outside political interests affect policy agendas and specifically policy implementation. 


\title{
Integrating Case Studies in an Online Asynchronous Learning Environment: An Empirical Study to Evaluate the Effect on the Perceived Community College Student Learning Outcomes and Engagement when Case Studies are Presented Using Virtual Reality
}

\begin{abstract}
This paper presents the results of an empirical study that evaluated the learning outcomes and student engagement when case studies are presented using virtual reality integrated into an online asynchronous learning environment developed using the Open edX codebase. Virtual reality systems are becoming more frequently used in educational settings primarily because of their ability to provide visualization and interaction within an environment that closely resembles a real-world setting. Both text-based and VR-based case studies were integrated into an online course on workplace safety. The online courses consisted of multiple short video-based lectures with assessments after each. Using a between-subjects experimental design, 109 community college students were randomly assigned to one of two conditions: (1) an online course with integrated case studies presented as text and images; (2) an online course with integrated case studies presented as virtual reality content. This latter condition presented the participants with a virtual manufacturing environment, asking them to navigate through it and determine the set of actions needing to be performed when encountering a potential safety infraction.
\end{abstract}

Students were given both pre- and post-tests to measure objective learning outcomes in addition to surveys for evaluating engagement and perceived learning outcomes. Statistically significant differences were found for engagement level and perceived learning outcomes. Thus, the results of this study suggest that presenting case studies using a virtual reality-based system can enhance these two educational priorities.

\section{Introduction}

While online learning environments are increasingly being used in current educational systems ${ }^{1-5}$, one of the key challenges associated with them is identifying and incorporating appropriate methods for preventing online learners from losing motivation and interest in their courses. ${ }^{6}$ Recent studies have identified that including audio, video and animation could mitigate these issues ${ }^{7,8}$. In addition, virtual reality (VR) based systems that use three dimensional (3D) computer graphics in combination with interface devices to create an interactive, immersive environment also offer opportunities for presenting difficult content in meaningful and engaging ways ${ }^{9}$.

Due to improvements in technology and reductions in cost, the use of VR in education has increased over the past ten years ${ }^{10,11,24}$, in part because it, and technology in general, is believed to facilitate learning through engagement, immersion and interactivity ${ }^{12}$ while at the same time providing a customized learning experience that can be accessed at the learner's convenience ${ }^{13}$. VR is viewed as especially promising because of its unique ability to immerse learners in the environments they are studying, such as in ancient cities or in the human body, and research into its effectiveness as a technology-based educational tool has demonstrated tangible benefits, including reduced learning time and improved learning outcomes ${ }^{11,14}$. Further, technologies 
such as VR have also expanded both access to educational opportunities as well as the range of programs that can be offered in an online setting.

Virtual environments are often classified as either desktop or immersive, with the former providing (3D) multimedia simulations that users enter and explore using typical computer hardware such as a mouse or trackpad. Immersive virtual environments expand these capabilities, utilizing advanced technology-based tools including head-mounted displays (HMD) and data gloves in addition to computer workstations ${ }^{15}{ }^{16}$. With the exception of military training activities where these and their related hardware are commonly used, desktop VR is the type typically used in the educational domain as it has the advantage of being more accessible and economical for widespread use. While immersion may be important for some types of learning activities, it is the level of interactivity, not the immersion, which is the primary feature needed for educational VR applications. Although some researchers have questioned the ability of a desktop VR setting for providing a real sense of presence, Dalgarno and colleagues suggested that presence is created by fidelity, level of interaction and user control rather than the specific characteristics of the virtual environment. ${ }^{17}$

Even though Clark ${ }^{18}$ has argued that the media will never influence learning outcomes, implying that there is nothing intrinsically beneficial to using VR in education, Kozma ${ }^{19}$ argued that the use of the correct media could impact students' cognitive skills and that the media itself is a critical component of instructional design. Dalgarno and Lee ${ }^{17}$ supported his contention, saying that the "technologies themselves do not directly cause learning to occur but can afford certain tasks that themselves may result in learning." Although studies have been published demonstrating the superiority of technology-based instruction over traditional classroom-based since the early 90s, including a meta-analyses on the effectiveness of computer-based training conducted by Kulik \& Kulik ${ }^{20}$, the subsequent questions have focused on what characteristics of the technology specifically lead to improved educational outcomes. A similar trend of research has been followed for VR, with early skeptics pointing out that the research on the effectiveness of the use of VR in education failed to identify specific features or characteristics of the environment that positively impact learning. ${ }^{17}$

More recent research on VR has addressed this issue, identifying specific characteristics of the technology that both improve learning outcomes as well as justify the cost of its adoption, with these studies finding a link between the use of computers and information technology and student engagement and learning outcomes. ${ }^{21,22}$ However, these studies investigated the general use of information technology instead of the specific use of instructional and learning management systems. ${ }^{22,23,24}$ This study addresses this limitation by investigating the nature of student engagement in an online learning environment to determine if content characteristics affect the use of the learning technologies and their impact on student engagement. It uses case studies, which include a detailed narrative of a situation involving fictitious or real people, allowing students to consider the real world issues they might face in a workplace. The potential of such case studies to enhance a student's understanding of the complexities of situations is well documented. However, the presentation of such case studies in an online asynchronous learning environment remains relatively unexplored. This study investigates the effect of content presentation in an online asynchronous learning environment on student engagement by comparing text-based scenarios with VR immersion depictions of safety procedures in a manufacturing environment. 


\section{Method}

Participants

The participants in this study included 109 students enrolled in XXXX Community College.

\section{Apparatus}

This study used a Dell OptiPlex desktop computer connected to the Internet, with each participant being provided with an appropriate headphone, keyboard and mouse. The online component for this research study was created on EducateWorkforce.com, a custom portal specifically designed for 2-year colleges for integrating web and digital solutions into their existing courses. This system was built using the Open edX codebase, an open source course management system (CMS) developed by edX that offers interactive online courses and Massive Open Online Courses (MOOCs). Although this platform is used extensively to host MOOCs, it also hosts smaller classes and training modules as well.

\section{Learning environments}

EducateWorkforce.com, an online learning platform specifically built for and tailored to the unique needs of 2-year institutions, consists of both basic and advanced courses focusing on the needs of technician education. The two courses created on this platform used here were (1) An asynchronous online learning environment where scenarios were incorporated as case studies and (2) An asynchronous online learning environment where scenarios were included as virtual reality-based modules. These are shown in Figure 1 below.

\section{Experimental design}

This study, which was approved by Clemson University’s Institutional Review Board, was conducted in a computer lab at Spartanburg Community College using students enrolled in the Computer Program Technology (CPT) 101 courses. The age range of participants varied, but all were full- or part-time students in two-year college educational programs.

The study used a between-subjects experimental design, with the students being randomly assigned to one of the two conditions: (1) The asynchronous online learning environment using the text-based case studies as the scenarios or (2) The asynchronous online learning environment where scenarios were included as virtual reality-based modules. At the beginning of the study, the participants signed an informed consent and were reminded that their participation was voluntary. They were then given a pre-course assessment. Next, they listened to the module on safety consisting of multiple lessons and responded to questions about the material. Specifically, the participants assigned to text-based condition viewed case studies along with figures on the unsafe safety practices in a manufacturing environment, while the students assigned to the virtual reality based condition were exposed to scenarios created using Virtual Reality (VR). 


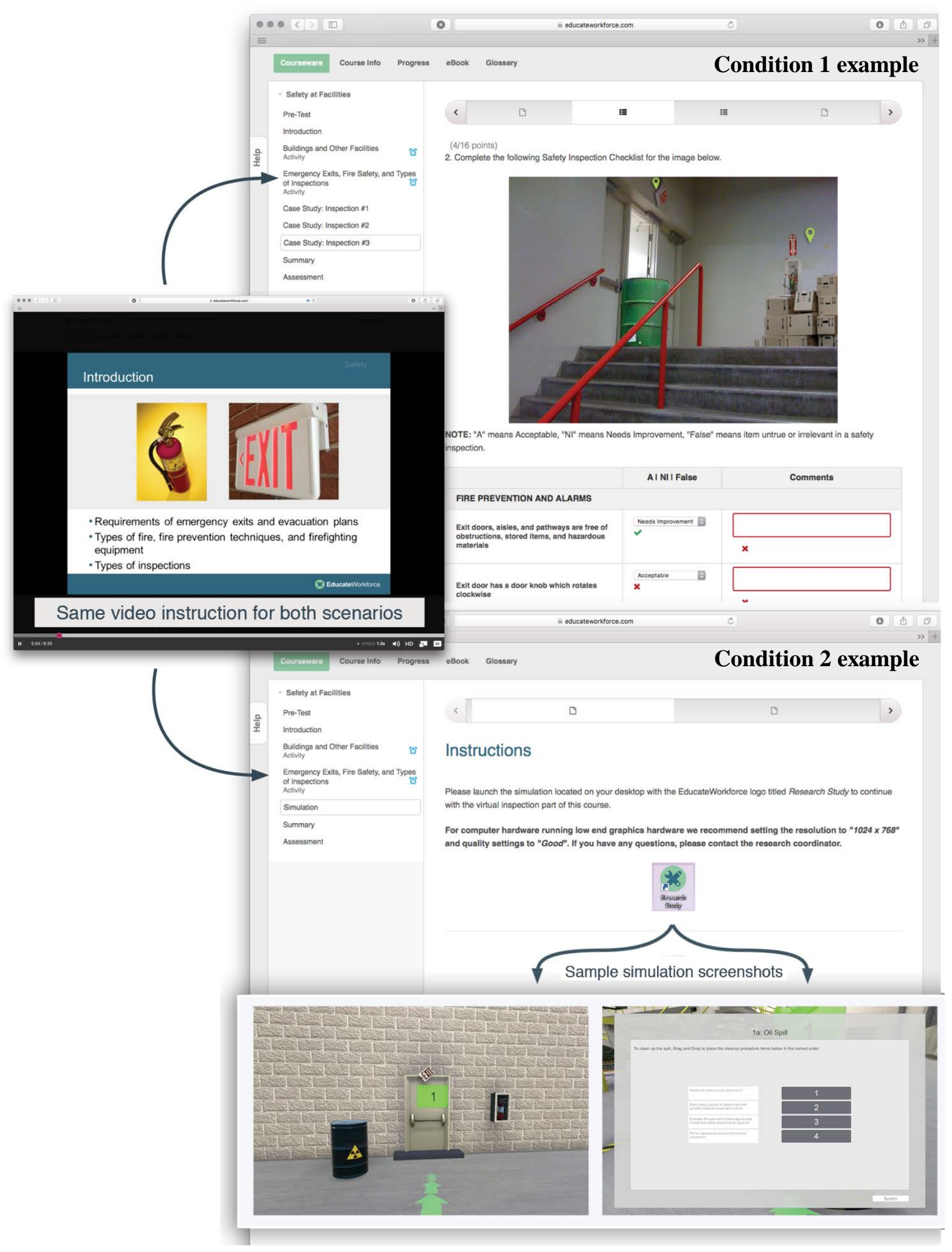

Figure 1. Stimuli 
Both sets of participants responded to questions about the material and completed a post-course assessment. The time taken to complete the study averaged between 60 and 90 minutes, and participants received a $\$ 10.00$ Amazon gift card upon its completion. The specific procedure used for this study is shown in Figure 2.

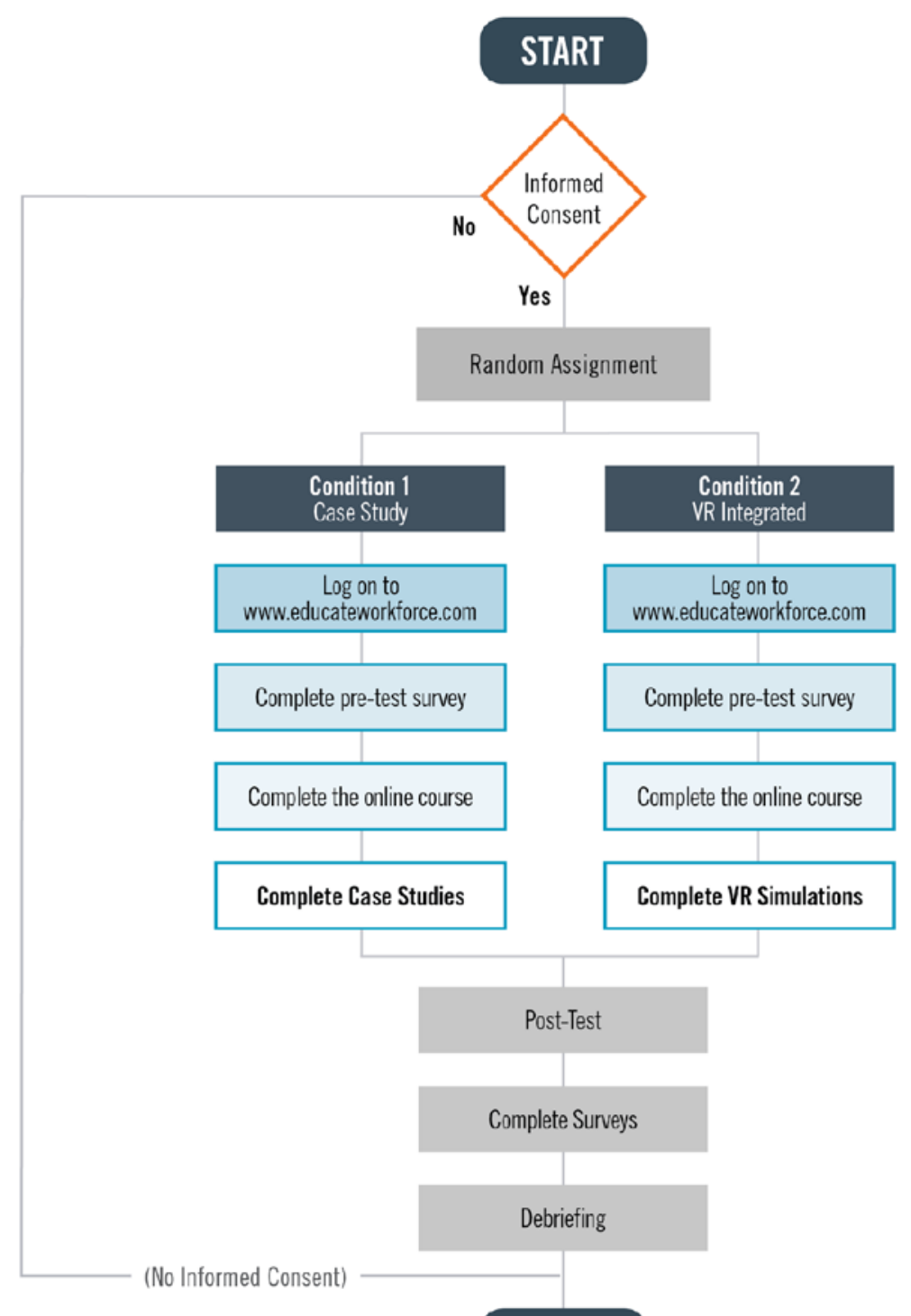

END

Figure 2. Study procedure

\section{Measures}

While the students in each condition completed a pre-test in class at the beginning of the study, the outcome of interest was the percentage of items the student answered correctly on the content specific post-test. In addition, students completed both a perceived learning outcomes and perceived engagement survey. 
Analysis

SPSS 22.0 was used to analyze the data. An independent-samples t-test was run to determine the differences, if any, between the two conditions. Initial analysis indicated no outliers in the data as assessed by inspection of a boxplot. The scores for each level were found to be normally distributed based on the Shapiro-Wilk's test, and the Levene's test for equality of variances indicated no homogeneity of variances.

\section{Results}

Perceived engagement levels: This construct was measured by averaging the Likert scale (seven point scale with " 1 ” being "Strongly disagree" and “7” being "Strongly agree”) responses to the questions: (1) This type of computer program allows me to be more responsive and active in the learning process, (2) This type of computer program allows me to have more control over my own learning, (3) This type of computer program promotes self-paced learning, (4) This type of computer program gets me engaged in the learning activities. The results found that the virtual reality based condition $(\mathrm{M}=5.14, \mathrm{SD}=0.71)$ allowed the participants to be more engaged than the text-based $(\mathrm{M}=4.30, \mathrm{SD}=1.03)$ case study condition, with a statistically significant difference of 95\% CI [ -1.17, -0.50], t (107) = -4.936; p < 0.001, as shown in Figure 3.

The four constructs used here to measure the perceived learning outcomes included (1) Ease of comprehension, (2) Ease of memorization, (3) Perceived ability to apply what was learned, and (4) Ability to better analyze problems.

Ease of comprehension: The perceived ease of comprehension was evaluated using the question, this type of computer program makes comprehension easier. The results found that the virtual reality-based condition $(\mathrm{M}=6.08, \mathrm{SD}=0.87)$ allowed the participants to comprehend better than the text-based $(\mathrm{M}=5.31, \mathrm{SD}=1.26)$ case study condition, with a statistically significant difference of 95\% CI [ -1.18, -0.37], t (107) = -3.784; p < 0.001, as shown in Figure 4.

Ease of memorization: The perceived ease of memorization was evaluated using the question, this type of computer program makes memorization easier. The results found that the virtual reality based condition $(\mathrm{M}=5.87, \mathrm{SD}=1.19)$ allowed the participants to memorize better than the text-based $(\mathrm{M}=4.87, \mathrm{SD}=1.42)$ case study condition, with a statistically significant difference of 95\% CI [ -1.51, -0.51], t (107) = -4.021; p < 0.001, as shown in Figure 5.

Perceived ability to apply what was learned: The perceived ability to apply what was learned was evaluated using the question, this type of computer program helps me to better apply what was learned. The results found that the virtual reality based condition $(\mathrm{M}=6.17, \mathrm{SD}=0.955)$ allowed the participants to better apply what was learned than the text-based $(\mathrm{M}=5.29, \mathrm{SD}=$ 1.33) case study condition, with a statistically significant difference of $95 \%$ CI [ $-1.33,-0.45], t$ $(107)=-4.009 ; \mathrm{p}<0.001$, as shown in Figure 6.

Ability to better analyze problems: The perceived ability to better analyze problems was evaluated using the question, This type of computer program helps me to better analyze the problems. The results found that the virtual reality-based condition $(M=6.01, S D=1.07)$ allowed the participants to better analyze the problems than the text-based $(M=5.31, S D=1.15)$ 


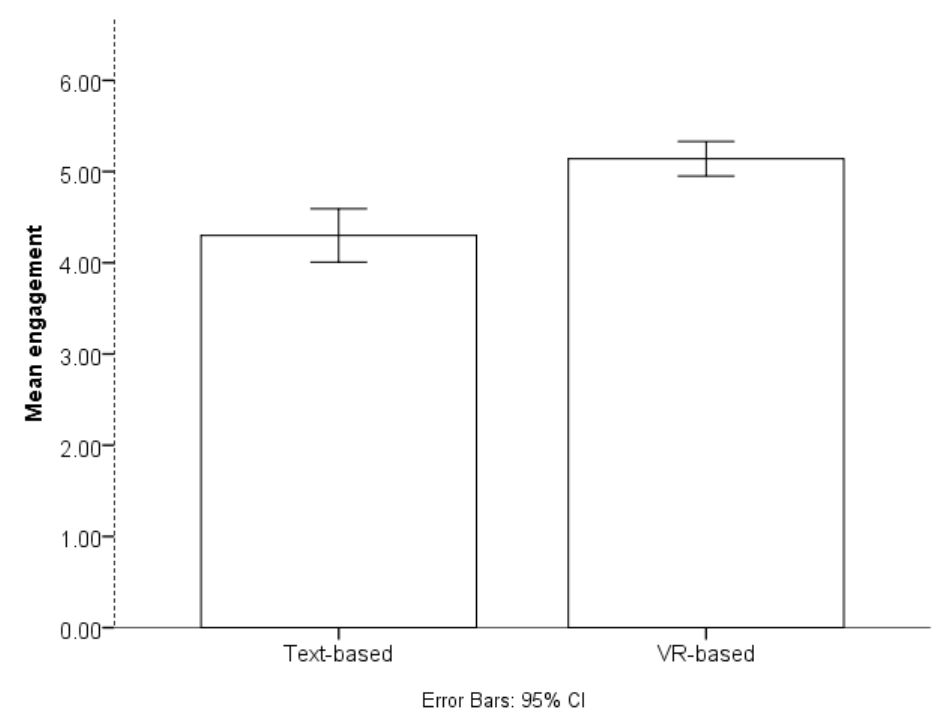

Figure 3: Mean engagement scores

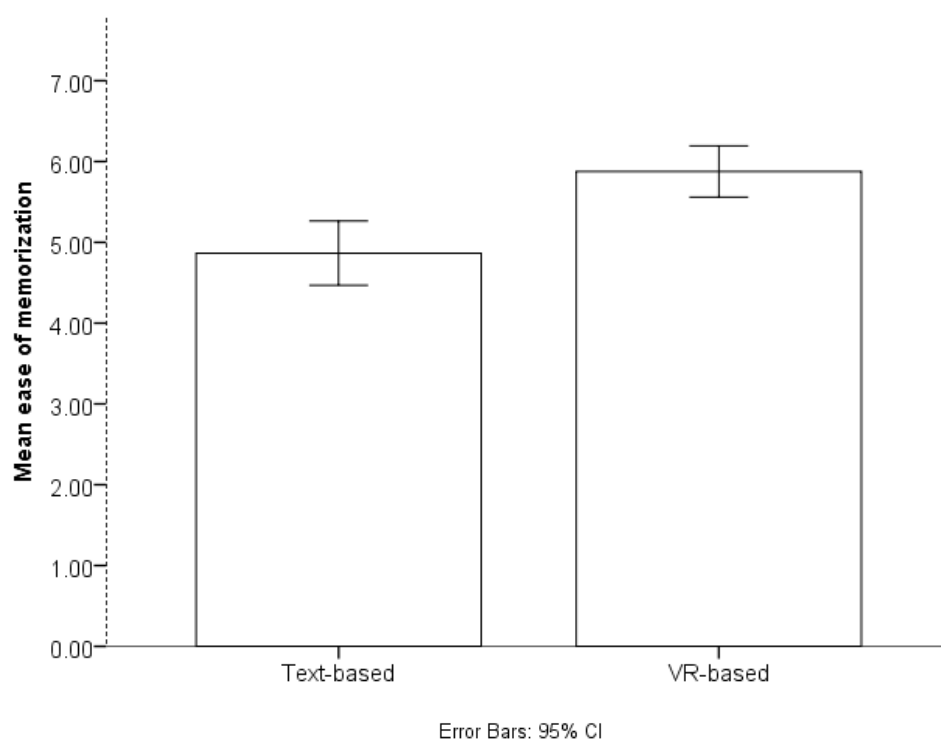

Figure 5: Mean ease of memorization scores

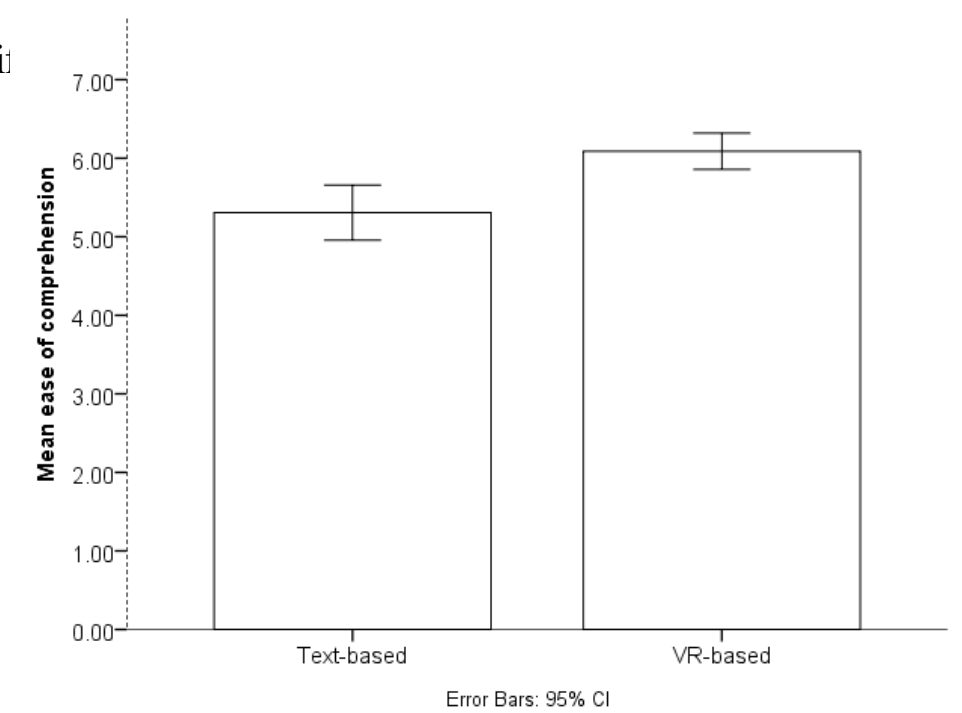

Figure 4: Mean ease of comprehension scores

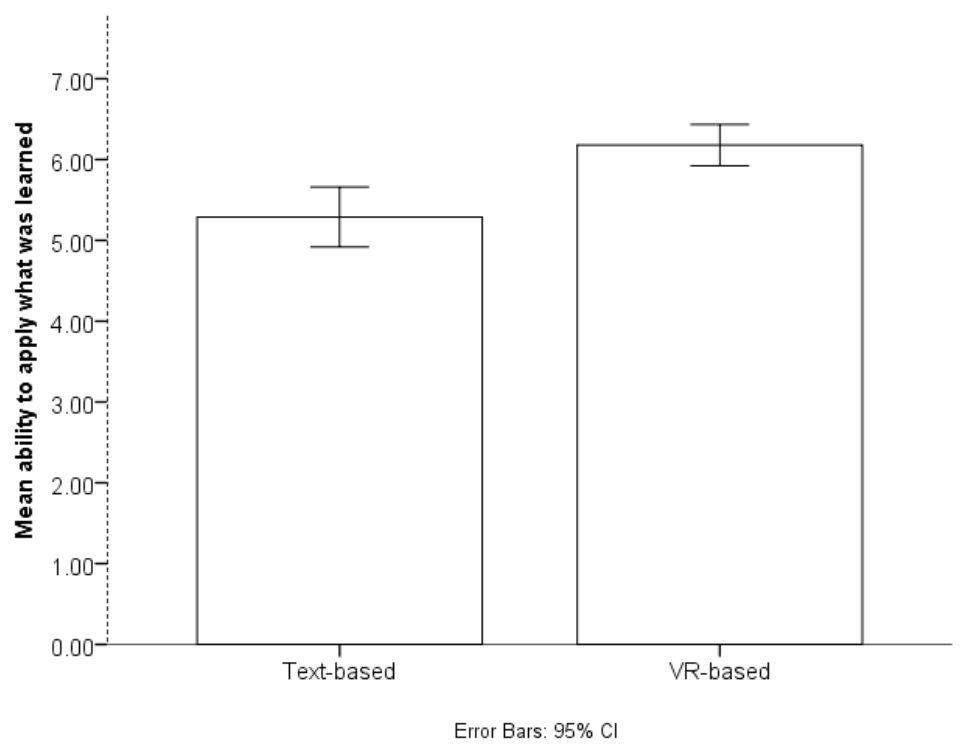

Figure 6: Mean ability to apply what was learned

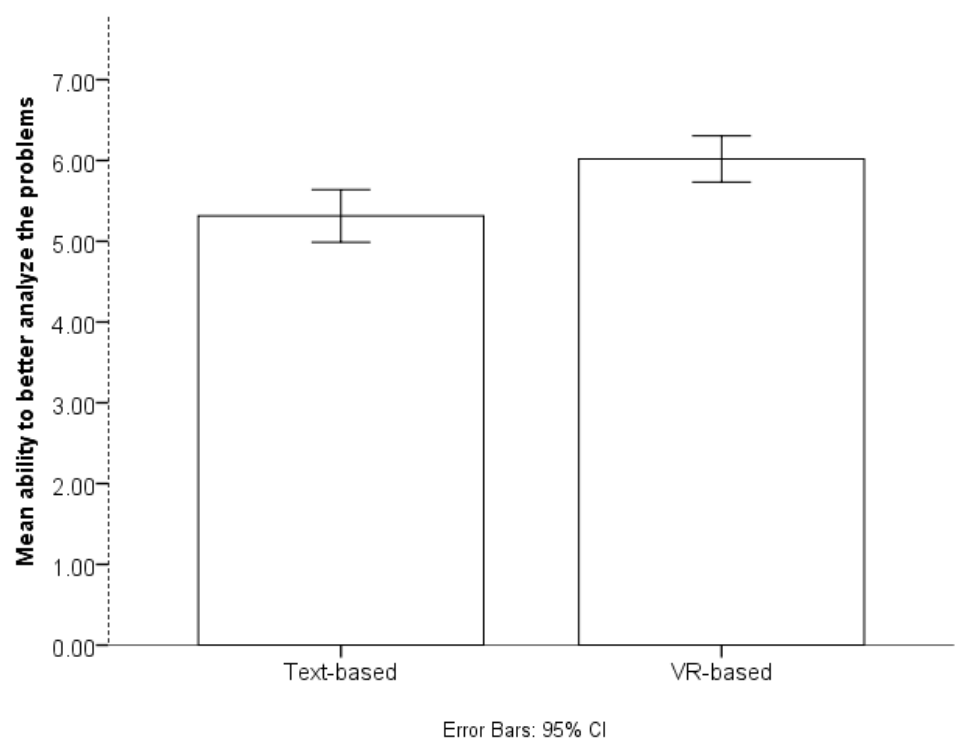

Figure 7: Mean ability to better analyze problems 
Objective learning outcomes: The results of the pre- and post-course surveys were used to evaluate the objective learning outcomes associated with the two conditions. The progress in the students' achievement was compared using the difference between the scores prior to and after taking the course. The results of this analysis suggested no significant differences between the two conditions for the objective learning outcomes.

\section{Discussion}

While asynchronous online learning provides more flexible access to educational materials in relation to both time and space than campus-based education, one of the key challenges of this learning environment is student content interaction. This study compared a text-based condition to an online virtual reality based system using scenarios involving safe practices in a manufacturing plant. No significant differences were identified for the overall learning outcomes measured using pre- and post-surveys. This could be due to the fact that all the required information was provided in both the conditions, meaning participants could have answered the questions. However, further analysis of the perceived engagement level suggests that participants preferred the virtual-reality based condition over the text-based alternative.

More importantly, participants found that the virtual reality based condition was easier to comprehend than the text-based condition, perhaps due to the immersive nature of this type of environment; as a result, it may have provided them with the ability to explore and better identify the impact of different infarctions on safety in a manufacturing environment. The study also found that the perceived ability to apply the learned material was higher for the VR-based condition than the text-based condition, a finding potentially related to the ability of virtual reality simulations to deliver highly realistic experiences. In this study, as participants walked through the scenario in the virtual environment, they experienced the various infarctions, becoming aware of their impact and the potential ways to mitigate it. This could be one of the reasons that the virtual reality based condition scored higher in terms of ease of memory and the perceived ability to apply the concepts learned. Statistically significant differences were found for the engagement level and the perceived learning outcomes, suggesting that presenting case studies using a virtual reality based system has the potential to enhance both of these.

However, this study is not without limitations. It was conducted using students enrolled in one course, CPT 101, from one community college in South Carolina. Additional studies are needed involving larger numbers of students from other technical colleges and from other courses and disciplines.

\section{Acknowledgments:}

This work was supported by the National Science Foundation under Grant No. 1104181. Any opinions, findings, and conclusions or recommendations expressed in this material are those of the author(s) and do not necessarily reflect the views of the National Science Foundation. 


\section{References}

1. Pantelidis, V. S. Virtual reality in the classroom. Educ. Technol. Res. Dev. (1993). at $<$ http://eric.ed.gov/?id=EJ462844>

2. Rizzo, A. A. et al. The Virtual Classroom: A Virtual Reality Environment for the Assessment and Rehabilitation of Attention Deficits. Cyberpsychol. Behav. 3, 483-499 (2000).

3. Auld, L. W. S. \& Pantelidis, V. S. Exploring virtual reality for classroom use. Tech Trends 39, 2931 (1994).

4. Youngblut, C. Educational Uses of Virtual Reality Technology. (DTIC Document, 1998). at <http://oai.dtic.mil/oai/oai?verb=getRecord\&metadataPrefix=html\&identifier=ADA339438>

5. Thorsteinsson, G. Developing an Understanding of the Pedagogy of Using a Virtual Reality Learning Environment (VRLE) to Support Innovation Education. The Routledge International Handbook of Innovation Education. Edited by LV Shavinina. Oxford: Routledge. ISBN-10 415682215, 456-470 (2013).

6. Tsai, F.-H., Tsai, C.-C. \& Lin, K.-Y. The evaluation of different gaming modes and feedback types on game-based formative assessment in an online learning environment. Comput. Educ. 81, 259-269 (2015).

7. Zyda, M. From visual simulation to virtual reality to games. Computer 38, 25-32 (2005).

8. Moreno-Ger, P., Burgos, D., Martínez-Ortiz, I., Sierra, J. L. \& Fernández-Manjón, B. Educational game design for online education. Comput. Human Behav. 24, 2530-2540 (2008).

9. Pan, Z., Cheok, A. D., Yang, H., Zhu, J. \& Shi, J. Virtual reality and mixed reality for virtual learning environments. Comput. Graph. 30, 20-28 (2006).

10. Manseur, R. Virtual reality in science and engineering education. in Frontiers in Education, 2005. FIE '05. Proceedings 35th Annual Conference F2E-8 (ieeexplore.ieee.org, 2005).

11. Ai-Lim Lee, E., Wong, K. W. \& Fung, C. C. How does desktop virtual reality enhance learning outcomes? A structural equation modeling approach. Comput. Educ. 55, 1424-1442 (2010).

12. Merchant, Z., Goetz, E. T. \& Cifuentes, L. Effectiveness of virtual reality-based instruction on students' learning outcomes in K-12 and higher education: A meta-analysis. Computers \& (2014). at <http://www.sciencedirect.com/science/article/pii/S0360131513002108>

13. Bellman, K. L. in Virtual Reality, Training's Future? 9-18 (Springer US, 1997).

14. Stone, R. J. in Haptic Human-Computer Interaction 1-16 (Springer Berlin Heidelberg, 2001).

15. Chalil Madathil, K. \& Greenstein, J. S. Synchronous remote usability testing: a new approach facilitated by virtual worlds. In Proceedings of the SIGCHI Conference on Human Factors in Computing Systems 2225-2234 (ACM, 2011).

16. Fernandes, K. J., Raja, V. H. \& Eyre, J. Immersive learning system for manufacturing industries. Comput. Ind. 51, 31-40 (2003).

17. Dalgarno, B. \& Lee, M. J. W. What are the learning affordances of 3-D virtual environments? Br. J. Educ. Technol. 41, 10-32 (2010).

18. Clark, R. E. Media Will Never Influence Learning. Educ. Technol. Res. Dev. 42, 21-29 (1994).

19. Kozma, R. B. Learning with media. Rev. Educ. Res. (1991). at $<$ http://rer.sagepub.com/content/61/2/179.short>

20. Kulik, C.-L. C. \& Kulik, J. A. Effectiveness of computer-based instruction: An updated analysis. Comput. Human Behav. 7, 75-94 (1991).

21. Papastergiou, M. Digital Game-Based Learning in high school Computer Science education: Impact 
on educational effectiveness and student motivation. Comput. Educ. 52, 1-12 (2009).

22. Laird, T. F. N. \& Kuh, G. D. Student experiences with information technology and their relationship to other aspects of student engagement. Res. High. Educ. 46, 211-233 (2005).

23. Chen, P.-S. D., Lambert, A. D. \& Guidry, K. R. Engaging online learners: The impact of Web-based learning technology on college student engagement. Comput. Educ. 54, 1222-1232 (2010).

24. Gramopadhye, A. K. \& Chalil Madathil, K. The Application of Advanced Technology to Education: The Aviation Inspection Example. In Proceedings of the 15th IASTED International Conference on Computers and Advanced Technology in Education, Napoli, Italy, (2012).

25. Bertrand, J. et al. The role of dimensional symmetry on bimanual psychomotor skills education in immersive virtual environments. in Virtual Reality (VR), 2015 IEEE 3-10 (2015). 